\title{
RISK ASSESSMENT IN THE EVALUATION OF IMPACTS \\ FROM POWER STATION STACK EMISSIONS
}

BJ Gore Technology Services International- Johannesburg

Dr W C van Niekerk INFOTOX cc- Pretoria

\section{INTRODUCTION}

In May 1997, the USA Environmental Protection Agency (USEPA) promulgated final rules that require oil and coal-burning electric power plants to report chemical releases under the national Toxic Release Inventory (TRI), established by Section 313 of the Emergency Planning and Community Right-to-Know Act (EPCRA) of 1986. This requires facilities in designated industry sectors to submit annual reports on the amounts of toxic chemicals released to the environment. The TRI is a publicly available database established to provide communities with information on the presence and releases of toxic chemicals [Rubin and Bedillion, 1998].

Approximately 300 substances were included on the original TRI list. The reporting requirements of TRI were expanded by the Pollution Prevention Act of 1990, which then included waste manage-ment and pollution prevention activities. As a result of this, in 1994, 286 substances were added to the TRI list, bringing the current total to 584 substances. Another expansion occurred in May 1997, when seven industry groups were added to the twenty sectors initially covered. The newly added industries included coal mining, commercial waste treatment and electric utilities. The final phase, which was to be enacted subsequently, was intended to require the addition of data on chemical usage, reporting requirements, as well as material accounting and worker exposure data.

Affected industries are identified by Standard Industrial Classification (SIC) categories. Electricity utility plants are in SIC codes 4911, 4931 and 4939. Any facility within a covered industry sector is required to report to TRI if it has the equivalent of ten or more full-time employees and manufactures" or "processes" more than 25 000 pounds of any listed toxic chemical during the reporting year, or "otherwise uses" more than 10 000 pounds of any listed chemical. A toxic chemical is considered to be processed if it is "prepared after manufacture for distribution in commerce". Finally, a chemical is considered to be otherwise used if its use does not fall under the categories of manufactured or processed.
Although electricity power stations are not chemical manufacturing industries, the TRI considers the combustion process to "manufacture" new chemicals from the trace constituents in coal or oil used to generate power. Such manufactured substances include not only volatile and semi-volatile organic compounds that are found in combustion emissions, but also metal oxides, anionic species andinorganic acids present in flue gas, fly-ash, bottom ash and particulate stack emissions. Coincidental manufacturing is considered by USEPA to have occurred any time a chemical substance in fuel is converted into a different chemical compound in the combustion gas or residual solids [USEPA, 1997]. For example, if any metal in coal is converted to its oxide, then that oxide is considered to have been manufactured in the process. Trace chemicals found in air intake and water streams are excluded from TRI reporting.

The Electric Power Research Institute (EPRI) developed software to assist in TRI reporting, It is known as the Power Plant Integrated System: Chemical Emissions Studies (PISCES) [Radian Corporation, 1992]. This consists of two parts:

- $\quad$ PISCES data base, developed by Radian International in the USA, contains empirical information on the concentration of trace chemicals found in fuels and in various power plant streams [Wetherold, 1995]. The data come from a variety of sources, including the EPRI's Field Chemical Emission Studies (FCEM) programme and the open technical literature.

- $\quad$ The PISCES Model, a mass and energy balance model that computes all chemical flows into and out of a user-specified power plant. Coal-fired, oilfired and gas-fired units are included. The model was developed originally to account for emissions of hazardous pollutants (HAPs), as well as trace chemicals in liquid and solid waste streams. A unique model feature is a probabilistic capability that allows uncertainties in plant parameters and mass flows to be quantified and modelled. To calculate emissions of trace substances, the model employs information from the PISCES database to quantify the trace substance removal efficiency of all plant components and emission control systems. 
Version 2.0 of the PISCES Model includes 35 trace chemicals selected on the basis of their potential relevance to the utility sector in the context of HAPs and TRI. The PISCES Model also contains extensive default information on the trace species concentration of fuels and reagents used by USA power plants.

\section{THE TSI POWER STATION SURVEY}

The regulations of the USEPA and relevant acts do not apply in South Africa, and there are currently no reporting requirements on the scale of the US TRI system in South Africa. Nevertheless, Eskom decided to acquire stack emission information within the framework of a TRI-type of reporting system. Eskom therefore commissioned TSI to conduct surveys to measure substances emitted from power station stacks for possible inclusion in the PISCES database and to use the data in the PISCES program for modelling. The idea was to assess the level of confidence with which PISCES can be used to predict stack emissions. INFOTOX was commissioned in the first phase of the studies to recommend the list of substances to monitor and to determine the minimum detection limits required for sampling and chemical analysis. After the power station survey, INFOTOX was contracted to conduct a quantitative environmental health risk assessment for communities in the areas that may be affected by emissions from a power station.

\section{APPROACH TO STUDY}

The terms of reference for this project was to conduct a screening-type health risk assessment. Screening assessments use worst-case assumptions and are not always based on the most realistic toxicological and epidemiological information, mainly because screening studies are designed to cost less than full risk assessments and therefore follow more simple approaches. As a rule in screening health risk assessments, speciation of a toxicant is not taken into account and bioavailability is assumed to be 100 per cent. Calculated health risks can therefore be overconservative. For the power station survey, it was reasoned that if risks on this basis were found low, it would not be necessary to refine the risk assessment to reduce uncertainties and make it less conservative.

The original paradigm for regulatory human health risk assessment in the USA was developed by the USA National Research Council [NRC, 1983]. This model divides human health risk assessment into the following steps:

- Hazard assessment is the identification of chemical and biological contaminants suspected to pose hazards and a description of the types of toxicity that they evoke.

- Dose-response assessment (toxicological assessment) addresses the relationship between levels of biological exposure and the manifestation of adverse health effects in humans and/or how humans can be expected to respond to different doses or concentrations of contaminants.

- Exposure assessment includes a description of the environmental pathways and distribution of hazardous substances, identification of exposed individuals or communities, the routes of direct and indirect exposure and the estimation of concentrations and duration of the exposure.

- Risk characterisation involves the integration of each component described above, with the purpose of determining whether specific exposures to an individual or a community would lead to adverse health effects.

More recent approaches for full risk characterisation examine hazard assessment, doseresponse assessment and exposure assessment in a more interactive way. The procedures involve knowledge of what is known and not known about the toxicant, its modes of action and effects in target tissue, what the assumptions and uncertainties are and the level of confidence in extrapolating from animals to humans and from high dose to low dose. This differs from the original stepwise concept of risk assessment, going from hazard assessment to dose-response assessment to exposure assessment and risk characterisation in an almost linear fashion. For screening health risk assessments, however, the original NRC paradigm is an acceptable basis for risk characterisation and was used as a framework in the current studies. It must be noted however, that where a screening health risk assessment indicates unacceptable health risks, it may be necessary to conduct a full risk assessment to avoid over-conservative factors that are normally associated with the screening risk assessment approach.

Where low concentrations of substances are determined in stack gas, it is likely that some of the target elements or compounds will not be

The Clean Air Journal Vol 11 No.1 May 2002 
observed, ie they will be assessed as present below the limits of quantification. This may present problems in the risk assessment step, where in the case of non-detected data points, fifty per cent of the method detection limit is used in the formulae to quantify the health risk. Where method detection limits are relatively high, this may lead to the prediction of unacceptable health risks, even where those substances were not observed. It was therefore essential to develop the survey plan on the basis of health-risk based method detection limits.

\section{HEALTH RISK ASSESSMENT}

\subsection{Hazard Assessment}

Table 1 below is a schedule of elements, which could occur in coal and form the basis of the risk assessment. Elements highlighted in bold italics and are elements of interest, based on their toxicological profiles. Elements in normal print are low in toxicity and are not significant for review.

A detailed assessment was made of each of the priority substances highlighted in bold italics and the risk factor, allowable ambient air levels and reference concentrations were identified. Although it is generally acknowledged that toxicity varies among compounds of an element where one or more of the compounds of an element are known to be toxic, USEPA concluded that all compounds of such an element should be included in the list. USEPA has also stated that in the absence of better site-specific information, metals that take part in the combustion process may be assumed to convert completely into the lowest molecular mass oxides of the particular metals [Rubin and Bedillion, 1998].

Table 1: Schedule of elements, which could occur in Coal

\begin{tabular}{|c|c|c|}
\hline \multicolumn{2}{|c|}{ SUBSTANCE IN COAL } & \multirow{2}{*}{$\begin{array}{c}\text { COMMENT } \\
\text { ON NON PRIORITY SUBSTANCES }\end{array}$} \\
\hline PRIORITY & NON PRIORITY & \\
\hline As (arsenic) & Ag (silver) & $\mathrm{AgO}$ low toxicity at environmental levels \\
\hline B (boron) & $\mathrm{Al}$ (aluminium) & $\mathrm{Al}_{2} \mathrm{O}_{3}$ low toxicity, assessed as nuisance dust \\
\hline Ba (barium) & & \\
\hline Be (beryllium) & Bi (bismuth) & $\mathrm{Bi}_{2} \mathrm{O}_{3}$ only slightly toxic by ingestion \\
\hline Cd (cadmium) & Ce (cerium) & Oxide insoluble, nontoxic \\
\hline Co (cobalt) & & \\
\hline Cr (chromium) & Cs (cesium) & $\mathrm{Cs}_{2} \mathrm{O}$ \\
\hline Cu (copper) & & \\
\hline Hg (mercury) & Fe (iron) & Some compounds are toxic, overall at low levels \\
\hline Mn (manganese) & & not significant \\
\hline $\mathrm{Ni}($ nickel) & $\mathrm{K}($ potassium $)$ & Toxicity normally that of the anion \\
\hline P (phosphorus) & Ga (gadolinium) & $\mathrm{Gd}_{2} \mathrm{O}_{3}$ low toxicity \\
\hline Pb (lead) & La (lanthanum) & $\mathrm{La}_{2} \mathrm{O}_{3}$ low toxicity \\
\hline Sb (antimony) & & \\
\hline Se (selenium) & Mg (magnesium) & Toxicity normally that of the anion \\
\hline Th (thorium) & Mo (molybdenum) & Oxide low in toxicity, normally assessed as \\
\hline U (uranium) & & nuisance dust \\
\hline V (vanadium) & $\mathrm{Na}$ (sodium) & Toxicity normally that of the anion \\
\hline Zn (zinc) & $\mathrm{Nb}$ (niobium) & $\mathrm{Nb}_{2} \mathrm{O}_{5}$ low toxicity \\
\hline Anions & Nd (neodymium) & $\mathrm{Nd}_{2} \mathrm{O}_{3}$ low toxicity \\
\hline Chloride & $\mathrm{Rb}$ (rubidium) & Not toxic at environmental levels \\
\hline Sulphate & Sc (scandium) & Low toxicity \\
\hline (sulphur oxides) & Y (Yttrium) & $\mathrm{Y}_{2} \mathrm{O}_{3}$ low toxicity \\
\hline Fluoride & Zr (zirconium) & Not toxic at environmental levels \\
\hline
\end{tabular}

\subsection{Toxicological Assessment}

\subsubsection{Particulates}

Ambient air quality guidelines have been set in many countries for total suspended particulates (TSP) and for particulates with an aerodynamic diameter of smaller than $10 \mu \mathrm{m}$ (PM-10). There is a weak association between PM-10 particulate matter and cardiopulmonary morbidity and mortality, although some studies suggest that this association is more strongly related to particulates $2.5 \mathrm{~mm}$ and smaller (PM-2.5) [Michaels and Kleinman, 1997]. 
Particulate matter is considered a criteria pollutant in the USA and is controlled also in other parts of the world. Ambient air quality guidelines or standards differ from country to country. The values listed below are representative of general levels and were used for assessment of the receptor area exposure scenario.

Total suspended particulates, annual geometric mean: $90 \mu \mathrm{g} / \mathrm{m}^{3}$ [IUAPPA, 1995]

Total suspended particulates, 24-hour maximum $350 \mu \mathrm{g} / \mathrm{m}^{3}$ [IUAPPA, 1995]

PM-10, annual geometric mean $50 \mu \mathrm{g} / \mathrm{m}^{3}$ (USA Federal Standard)

PM-10, 24-hour maximum $150 \mu \mathrm{g} / \mathrm{m}^{3}$ (USA Federal Standard)

Particle size distributions were not determined during the power station stack emission survey. As a worst-case assumption, all the particulates were taken as $\leq 10 \mu \mathrm{m}$ (PM10). The USA guidelines were used for the calculation of hazard quotients.

A problem in risk interpretation is that particulates are treated as a precisely defined entity, which they are not. Particulates have multiple sources, a wide distribution of sizes and different chemistry and surface area attributes. It is therefore not possible to quantify all potential health effects purely on the ambient air particulate load. In the current health risk assessment, the potential for health impacts as a result of particulate emissions and dispersion from the site, has been interpreted in a more quantitative manner, taking into account that hazardous constituents in particulates may play a prominent role in the manifestation of health effects.

\subsubsection{Gaseous emissions}

Information on Guideline exposures was evaluated for:

- Three oxides of nitrogen normally encountered in the atmosphere are nitrous oxide $\left(\mathrm{N}_{2} \mathrm{O}\right)$, nitric oxide $(\mathrm{NO})$ and nitrogen dioxide $\left(\mathrm{NO}_{2}\right)$.

- Short-term guidance value: $200 \mu \mathrm{g} / \mathrm{m}^{3}$ (hourly maximum).

- Long-term guidance value: $40 \mu \mathrm{g} / \mathrm{m}^{3}$ (annual average).

- Sulphur dioxide, a moderate to strong irritant.

- A 1-hour guideline of $1300 \mu \mathrm{g} / \mathrm{m}^{3}$,

- the WHO maximum annual guideline of $50 \mu \mathrm{g} / \mathrm{m}^{3}$
- $\quad$ Fluorides, regulatory authorities have not developed ambient air quality guidelines for hydrofluoric acid, the primary compound of concern where fluorides are present.

- An ambient air concentration for 24hour exposures of $0.015 \mathrm{mg} \mathrm{HF} / \mathrm{m}^{3}$, or $0.014 \mathrm{mg} \mathrm{F} / \mathrm{m}^{3}$.

\subsubsection{Volatile and Semi-Volatile Organic Compounds}

Full-scan gas chromatography-mass spectrometry data were acquired on the collected samples and a wide range of compounds was detected. The approach was not based on target substances, as was the case with the metals. Because most of the organic compounds were at low concentrations, a data reduction stepwas included to select only those compounds that were relevant for risk assessment.

Toxicological parameters were identified for Benzene, Dibenzofuran, Dichlorobenzene, Methylnaphthalene, Naphthalene, Pyridene, Tetrachloroethylene and Toluene. In most cases the reference concentrations were selected from the USEPA IRIS database. Whilst this database has some limitations, the data have been peer reviewed and in most cases are on the conservative side, tending to overestimate risk. The approach followed in this risk assessment is therefore considered to be adequate for a screening study.

\subsubsection{Aldehydes}

Toxicological parameters were identified for Benzaldehyde and Formaldehyde

\subsection{Exposure assessment}

\subsubsection{The exposure scenario}

The exposure assessment for the current human health risk assessment followed a simplified approach with regard to the characterisation of the exposed community. Various potential exposure pathways and exposure routes are illustrated in Figure1.

It was reasonable to asume that the most significant pathway of exposure was through air dispersion of toxicants in dust or gaseous form from the power station stacks. The shaded cells in Figure 1 indicate this pathway in the overall exposure scenario. 
The potential for exposure through polluted water and indirectly through the food chain was considered to be low. Inhalation was identified as the most significant route of exposure. Ingestion of contaminated soil, especially by children, may be a factor to consider, but this was expected to have a low impact in the overall scenario. Inhalation of re-suspended contaminated dust from the residential areas was also considered to be of lower significance. The community was regarded as a generic population, without taking into account aggravating factors or behaviour and activity patterns that could affect exposure. Indoor and outdoor air were assumed to have similar potentials for exposure.

Background concentrations of toxicants from other sources were not considered. Health risks due to environmental pollution from the Eskom power station source should therefore be interpreted as excess risks, ie health risks additional to the risks due to background pollution.

\section{CONCLUSIONS}

This environmental health risk assessment was based on concentrations of the substances of interest which were selected to represent the highest possible levels rather than averages or median values. The emissions data used for modelling and risk assessment were on the conservative side. The following aspects are of interest:

\subsection{Particulates}

At low ambient air concentrations, an increase in particulates, especially for the respirable fraction, has been linked in various studies in the world to an increase in hospitalisation rate for respiratory illness (Anderson et al, 1998; Stedman et al, 1999; Walters et al, 1995). This is more notable in respiratory compromised individuals such as asthmatics. The contribution of the power station to particulates in ambient air was however shown to be low and it is not expected that any measurable effects would be observed in communities in the receptor areas, even in those areas with the highest predicted particulate levels.

\subsection{Gaseous Emissions and Substances with Short- term Effects}

Increases in sulphur dioxide and nitrogen dioxide levels in communities have been shown to lead to increases in hospitalisation rates for respiratory illnesses (Anderson et al, 1998; Stedman et al, 1999; Walters et al, 1995). This may occur even at levels below ambient air quality guidelines. For $\mathrm{SO}_{2}$, guideline concentrations were not exceeded in the area of maximum possible exposure. The highest hourly average levels of $\mathrm{NO}_{2}$ were exceeded, but on average over a year the concentrations were an order of magnitude below the annual guideline. It is therefore unlikely that significant health effects would be traceable to $\mathrm{SO}_{2}$ and $\mathrm{NO}_{2}$ released from the power station stacks at the predicted ambient air concentrations, assuming low background levels in the area.

\subsection{Other Substances}

Systemic toxicants were emitted at relatively low concentrations and it is reasonable to conclude that health risks as a result of exposure to this category of compounds would be insignificant. USEPA recommends that hazard quotients be added per target organ, to get an overall hazard quotient. In each category, a hazard quotient exceeding 1 indicates an exposure situation that may be of concern. In the assessment of the power station emissions, hazard quotients for all the other substances were added, irrespective of their effects on different target organ systems and the overall hazard quotient was still below 1 .

\section{ACKNOWLEDGMENT}

Eskom Research Division is gratefully acknowledged for its continued research funding and ongoing support for the programme of General Risk Assessment of Power Plant Emissions from which the infor-mation for this paper has been obtained. Eskom is also thanked for permission to publish this paper. 
HUMAN EXPOSURE THROUGH MULTIPLE PATHWAYS THE EXPOSURE SCENARIO

$\rightarrow \quad$ Denotes potentially complete and significant pathways and exposure routes.

$\uparrow \quad$ Denotes insignificant or incomplete pathways and exposure routes.

$4 \quad$ Denotes the potential for irritation effects.

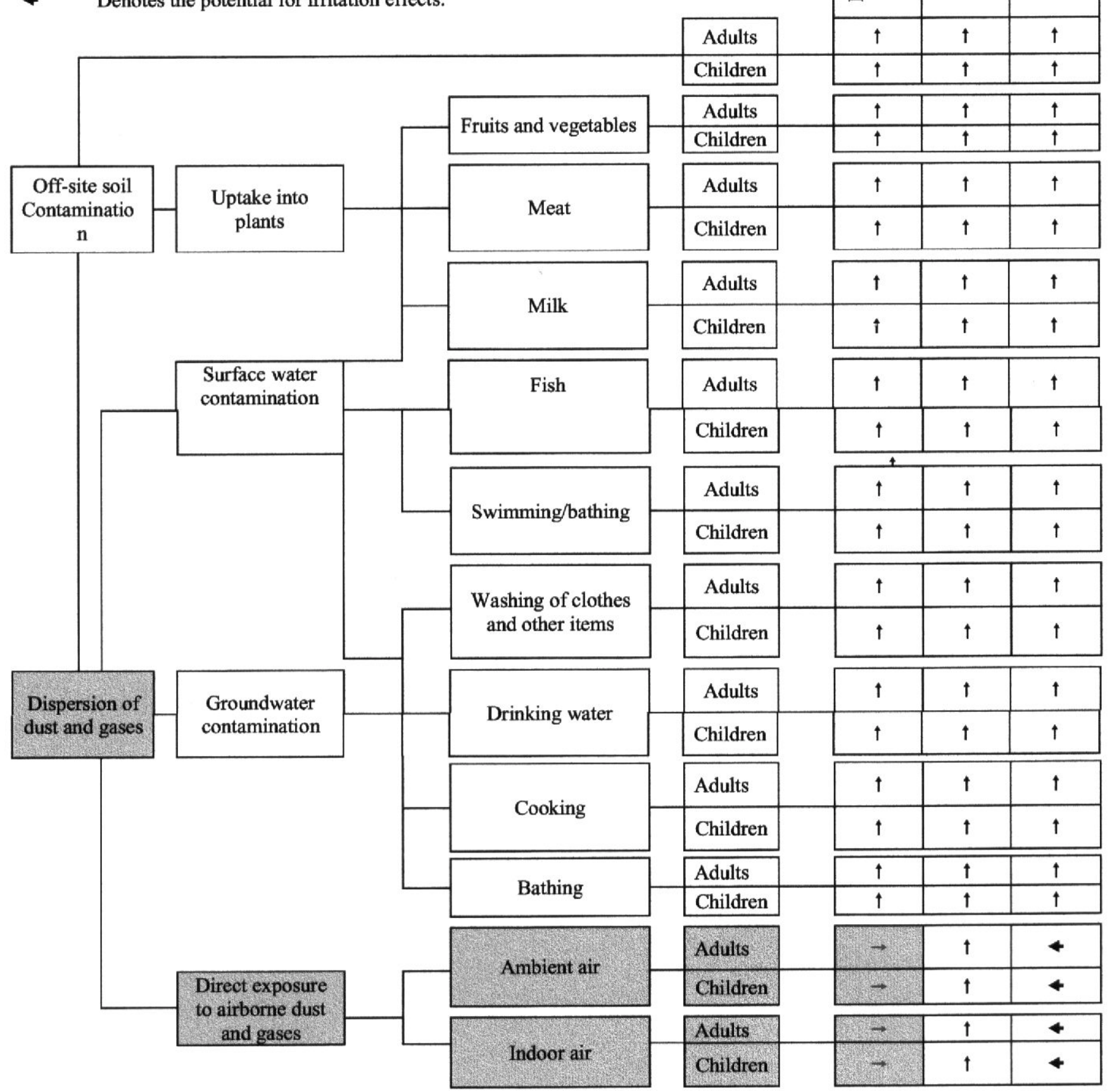

Figure 1: The complete environmental exposure scenario.

\section{REFERENCES}

Calabrese E J and Kenyon E M, 1991. Air Toxics and Risk Assessment. Lewis Publishers, Inc.
Chang LW, et al, 1996. Toxicology of Metals. CRC Lewis Publishers.

EPRI, 1994. Field Chemical Emissions Monitoring (FCEM) GenericSampling and 
Analytical Plan. Radian Corporation, Palo Alto, California. Report No RCN 213-152-40-08.

Hall S K, Chakraborty J and Ruch, 1997. Chemical Exposure and ToxicResponses. CRC Lewis Publishers.

HEAST, 1994. Health Effects Assessment Summary Tables. Annual update. USEPA Office of Research and Development, Cincinnati, Ohio.

IRIS, 1999. International Risk Information System. US Environmental Protection Agency, on-line database. http://www.epa.gov/

Kelly K E, 1991. The myth of 10-6 as a definition of "acceptable risk". 84 ${ }^{\text {th }}$ Annual Meeting of the Air and Waste Management Association, Vancouver.

NCR, 1983. Risk Assessment in the Federal Government: Managing the Process. National Research Council, Committee on the Institutional Means for the Assessment of Risks to Public
Health, National Academy Press, Washington, DC.

Patrick D R, 1994. Toxic Air Pollution Handbook. Van Nostrand Reinhold.

Radian Corporation, 1992. Evaluation of Emissions Information in the PISCES Database. Radian Corporation, Palo Alto, California. Report No DCN 92-213-161-02.

Rubin E S and Bedillion M D, 1998. A Comprehensive Approach to Power Plant Toxic Release Inventories. Presented at the Air \& Waste Management Association's 91st Annual Meeting and Exhibition, June 14-18, San Diego, California.

Smith R L, 1996. Risk-based Concentrations: Prioritizing Environmental Problems Using Limited Data. Toxicology, 106, 243.

WHO, 1999. Air Quality Management, Air Quality Guidelines. World Health Organisation. http://www.who.int/peh/air/airguidelines2.htm. 